\title{
A Biocompatible Method of Decorporation: Bisphosphonate Modified Magnetite Nanoparticles to Remove Uranyl lons from Blood
}

\author{
Ling Wang, Zhimou Yang, Jinhao Gao, Keming Xu, Hongwei Gu, Bei Zhang, Xixiang \\ Zhang, Bing $\mathrm{Xu}^{*}$
}

\section{Supporting Information}

Materials. 3-(3,4-bis(benzyloxy)phenethylcarbamoyl) propanoic acid (1), tetraethyl 3amino-propane-1,1-bisphosphonate (2), and $\mathrm{Fe}_{3} \mathrm{O}_{4}$ nanoparticles were prepared according to the literatures. ${ }^{1,2}$ O-benzotriazol-1-yl-N, N, N', N'-tetramethyluronium hexafluorophosphate (HBTU), N, N-diisopropylethylamine (DIEA) and bromotrimethylsilane (TMSBr) were bought from Fluka. All the other starting materials were obtained from Sigma-Aldrich or Acros. Commercially available reagents were used without further purification unless stated otherwise. Water was purified by Barnstead/Thermolyne Nanopure Diamond Life Science (UV/UF) ultrapure water system.

General methods. ${ }^{1} \mathrm{H},{ }^{31} \mathrm{P}$ NMR spectra were obtained on Bruker ARX 300. The nanoparticle samples were cryo-dried for transmission electron micrograph (TEM) analysis. TEM was recorded on JEM 2010. Time-of-flight Secondary Ion Mass Spectrometer (ToF-SIMS) was analyzed on Model PHI 7200 equipped with Cs and Ga ion guns for positive and negative ion mass detection. Inductively coupled plasma-optical emission spectrometer (ICP-OES) was recorded on Perkin-Elmer Optima 2000.

\section{A) Synthesis}

Synthesis of $\mathbf{3}$ :

HBTU (379 $\mathrm{mg}, 1 \mathrm{mmol})$ and DIEA $(0.9 \mathrm{~mL}, 5 \mathrm{mmol})$ were quickly added into a mixture solution of 1 (433 mg, $1 \mathrm{mmol})$ and $2(331 \mathrm{mg}, 1 \mathrm{mmol})$ in $6 \mathrm{ml}$ of DMF. After stirring for $24 \mathrm{hrs}$, the resulting solution was extracted with water and chloroform. The organic layer was collected and dried with sodium sulfate. The solvent was then evaporated in vacuum to get the crude product. $470 \mathrm{mg}$ of pure product was obtained with silica gel chromatography purification (yield: $67 \%) .{ }^{1} \mathrm{H}$ NMR $\left(300 \mathrm{MHz}, \mathrm{CDCl}_{3}\right): \delta 7.45-7.26(\mathrm{~m}$, $10 \mathrm{H}), 6.88-6.85(\mathrm{dd}, 2 \mathrm{H}), 6.80(\mathrm{~d}, 1 \mathrm{H}), 5.14(\mathrm{~d}, 4 \mathrm{H}), 4.18-4.11(\mathrm{q}, 8 \mathrm{H}), 3.44-3.38(\mathrm{t}, 4 \mathrm{H})$, 2.71-2.66(t, 2H), 2.46-2.42(t, 4H), 2.18-2.16(m, 3H), 1.35-1.27(t, 12H) ppm. ${ }^{31} \mathrm{P}$ NMR: 23.33 ppm. MS: calc. $\mathrm{M}^{+}=746$, obsvd. $(\mathrm{M}+1)^{+}=747$.

DA-BP (4). $470 \mathrm{mg}$ of 3 was dissolved in $10 \mathrm{~mL}$ of methanol and $200 \mathrm{mg}$ of the catalyst $\left(10 \% \mathrm{Pd}\right.$ on charcoal) was added under $\mathrm{N}_{2}$ atmosphere. Then the reaction proceeded at room temperature under hydrogen atmosphere for $18 \mathrm{hrs}$. After that the catalyst was filtered off and the resulting solution was evaporated to get the intermediate which was used without further purification. Then, the intermediate was treated with 3 equiv. of $\mathrm{TMSBr}$ in dry chloroform under stirring for $24 \mathrm{hrs}$. Reaction progress was monitored by TLC. Afterward, the solvent was evaporated under vacuum. Then, dry acetone with a small excess of water was added and stirred for another $30 \mathrm{~min}$. After removing the mixture solvent, a light yellow solid was obtained. The $454 \mathrm{mg}$ of pure product was obtained through precipitating from the basic aqueous solution of crude product by 
acidification (yield: almost 100\%). ${ }^{1} \mathrm{H}$ NMR $\left(300 \mathrm{MHz}, \mathrm{D}_{2} \mathrm{O}\right): \delta$ 6.87-6.84(d, $\left.1 \mathrm{H}\right), 6.79$ 6.78(d, 1H), 6.70-6.68(d, 1H), 3.40-3.35(t, 4H), 2.70-2.65(t, 2H), 2.44-2.40(t, 4H), 2.322.24(m, 1H), 2.06-2.01(m, 2H) ppm. ${ }^{31} \mathrm{P}$ NMR:21.48 ppm. MS: calc. $\mathrm{M}^{+}=454$, obsvd. $(\mathrm{M}+1)^{+}=455$.

$\mathrm{Fe}_{3} \mathrm{O}_{4}$-DA-BP (5). $5 \mathrm{mg}$ of 4 dissolved in $5 \mathrm{~mL} \mathrm{H}_{2} \mathrm{O}$, and $\mathrm{pH}$ value was adjusted to 5 . Then $5 \mathrm{~mL}$ of $\mathrm{Fe}_{3} \mathrm{O}_{4}(2 \mathrm{mg} / \mathrm{mL})$ in hexane was mixed with it to react under sonication for $30 \mathrm{~min}$. Then the aqueous phase was separated and washed with hexane $(3 \times 5 \mathrm{~mL})$.

$\mathrm{Fe}_{3} \mathrm{O}_{4}$-DA-BP-UO ${ }_{2}{ }^{2+}(6)$. The particles obtained in the previous step was added into 5 $\mathrm{mL}$ of $\mathrm{UO}_{2}\left(\mathrm{NO}_{3}\right)_{2}$ solution $(1 \mathrm{M})$ and stirred for $1 \mathrm{hr}$. Then, the product was separated from the solution with a small permanent magnet and washed with water two times.

\section{B) Removing uranyl ion from blood}

First, we added uranyl nitrate into $1.0 \mathrm{~mL}$ of blood $(100 \mathrm{ppm})$ and applied 5 minutes' sonication to make a homogeneous solution (I). Then we added $15 \mathrm{mg}$ of 5 into the solution and applied 30 minutes' sonication to ensure the sufficient interaction between $\mathbf{5}$ and $\mathrm{UO}_{2}{ }^{2+}$. Afterward, we used a small magnet to attract and remove the magnetic nanoparticles from the blood and washed the nanoparticles with water three times. We combined the blood and washings as part II and collected the magnetic nanoparticles as part III. Before ICP analysis, we added $5.0 \mathrm{~mL}$ of concentrated nitric acid to each sample first. Then we burned each sample to dryness by a gas stove and further burned the sample in muffle oven at $900{ }^{\circ} \mathrm{C}$ for 5 hours to remove remained organic compounds. Finally, the residue in each sample was dissolved in $5 \mathrm{~mL}$ of $\mathrm{HNO}_{3}(2 \mathrm{~N})$ for test.

\section{C) Characterizations}

Determine the number of DA-BP on the surface of each nanoparticle. We measured the weight of the nanoparticles that were transferred into aqueous phase and the amounts of the DA-BP that were taken up by magnetite nanoparticles. Using the sizes compositions of the nanoparticles, we estimated the number of DA-BP on the surface of each nanoparticle. Table $\mathrm{S}-1$ shows the result.

Table S-1. The estimated number of DA-BP on the surface of each nanoparticle.

\begin{tabular}{|l|c|}
\hline Nanoparticle & $\mathrm{Fe}_{3} \mathrm{O}_{4}$ \\
\hline Average size $(\mathrm{nm})$ & 8 \\
\hline Total weight of particles $(\mathrm{mg})$ & 100 \\
\hline Total \# of particles & $7.8 \times 10^{16}$ \\
\hline Total weight of DA-BP $(\mathrm{mg})$ & 3.2 \\
\hline Total \# of DA-BP & $4.2 \times 10^{18}$ \\
\hline \# of DA-BP per particle & $\sim 54$ \\
\hline
\end{tabular}



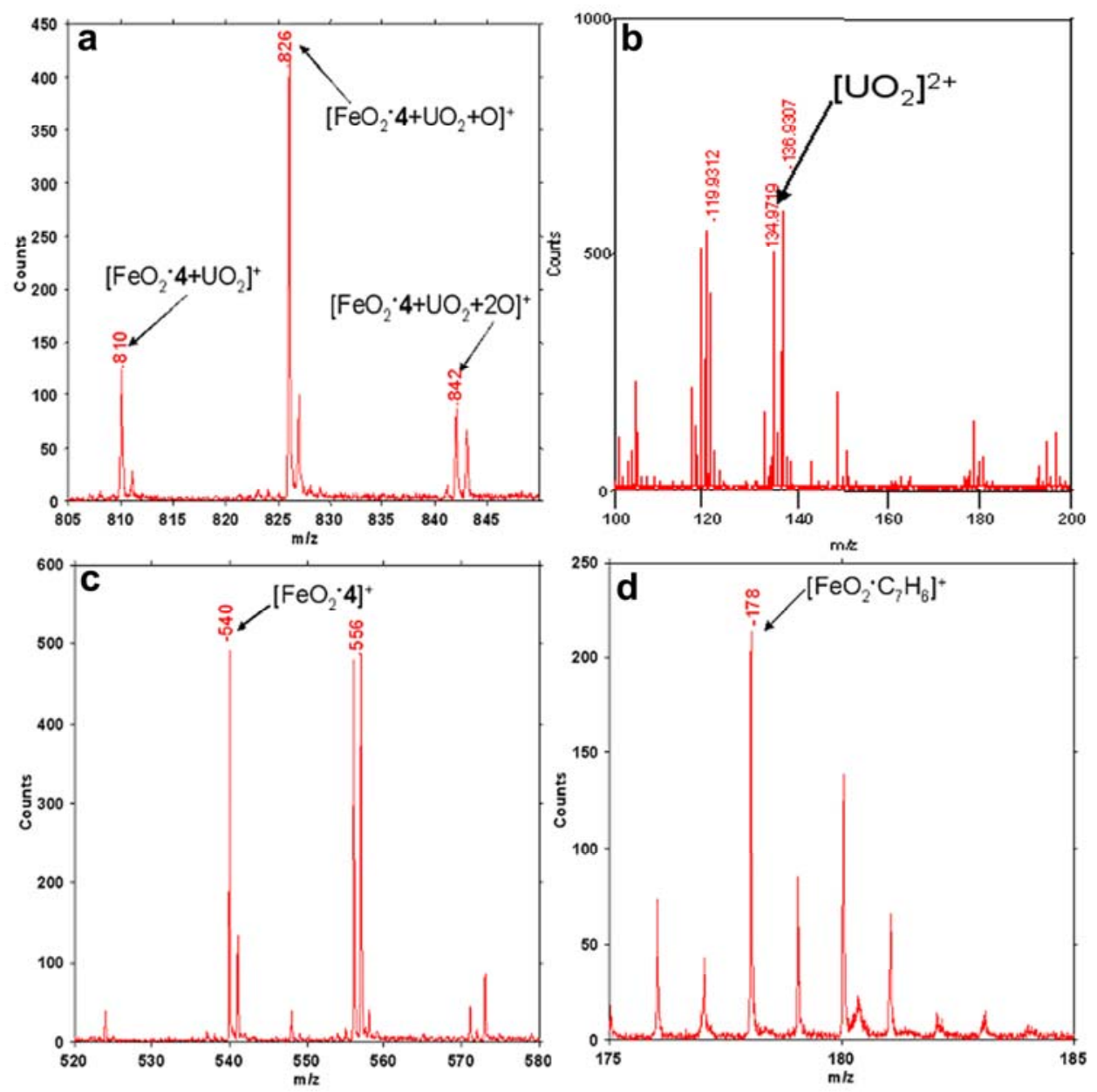

Fig. S-1. ToF-SIMS results for (a, b) $\mathrm{Fe}_{3} \mathrm{O}_{4}-\mathrm{DA}-\mathrm{BP}_{-} \mathrm{UO}_{2}{ }^{2+}$ and (c, d) $\mathrm{Fe}_{3} \mathrm{O}_{4}-\mathrm{DA}-\mathrm{BP}$.

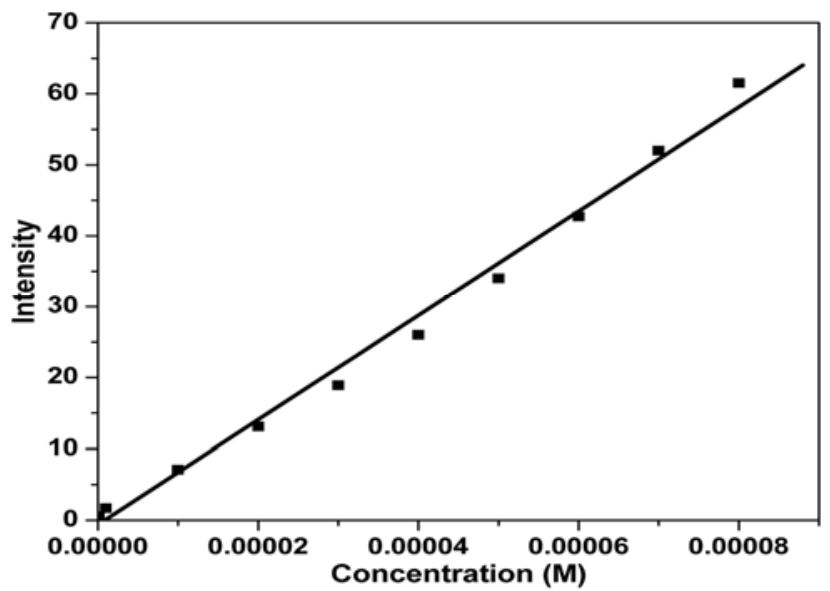

Fig. S-2. Calibration curve of $\mathrm{UO}_{2}{ }^{2+}$ got by fluorescent spectra $\left(\lambda_{\mathrm{ex}}=270 \mathrm{~nm}\right)$ method.

\section{The partitioning coefficient $K_{d}$}


The partitioning coefficient was determined from the initial, $\mathrm{C}_{\mathrm{i}}$, and final, $\mathrm{C}_{\mathrm{f}}$, aqueous phase counts as

$\mathrm{K}_{\mathrm{d}}=\frac{\left(\mathrm{C}_{\mathrm{i}}-\mathrm{C}_{\mathrm{f}}\right) \times \mathrm{V}}{\mathrm{C}_{\mathrm{f}} \times m}$

where $\mathrm{V}$ is the volume of initial aqueous phase in milliliters, and $\mathrm{m}$ is the mass of particles in grams.

Table S-2. The partitioning coefficient $\left(\mathrm{K}_{\mathrm{d}}\right)$ for systems in this paper.

\begin{tabular}{|c|c|c|c|c|c|}
\hline System & $\mathrm{C}_{\mathrm{i}}$ & $\mathrm{C}_{\mathrm{f}}$ & $\mathrm{V}(\mathrm{mL})$ & $\mathrm{m}(\mathrm{g})$ & $\mathrm{K}_{\mathrm{d}}(\mathrm{mL} / \mathrm{g})$ \\
\hline Water $^{\mathrm{a})}$ & $10^{-4} \mathrm{M}$ & $10^{-6} \mathrm{M}$ & 1 & 0.005 & 19800 \\
\hline Blood $^{\mathrm{b})}$ & $100 \mathrm{ppm}$ & $27 \mathrm{ppm}$ & 1 & 0.015 & 180 \\
\hline
\end{tabular}

a) Here $\mathrm{pH}=7.0$ and test after mixture with $\mathbf{5}$ for $30 \mathrm{~min}$;

b) Here $\mathrm{pH}=7.0$ and test after mixture with $\mathbf{5}$ for $30 \mathrm{~min}$.

\section{The magnetic moments of 5 and 6}

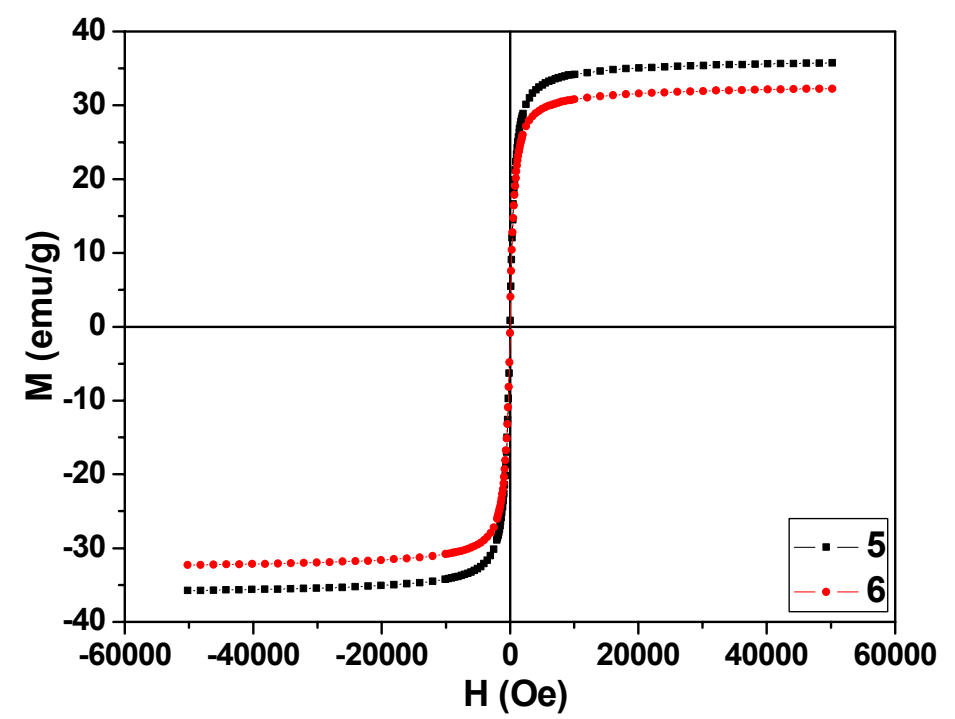

Fig. S-3. The magnetic moments of $\mathbf{5}$ and $\mathbf{6}$ at room temperature.

\section{References}

1. W. Winckler, T. Pieper and B. K. Keppler, Phosphorus Sulfur and Silicon and the Related Elements, 1996, 112, 137-141.

2. C. J. Xu, K. M. Xu, H. W. Gu, R. K. Zheng, H. Liu, X. X. Zhang, Z. H. Guo and B. Xu, J. Am. Chem. Soc., 2004, 126, 9938-9939. 